\title{
HERNIA OF THE SMALL INTESTINE INTO A PERSISTENT GREAT OMENTAL CAVITY
}

\author{
JOHN LOCKE WORCESTER
}

Anatomical Laboratory, University of Michigan

In the regular course of dissection in the Anatomical laboratory of the University of Michigan there was noted by the writer a subject in which after opening the abdominal cavity - with parts still in situ - it was observed that the greater part of the small intestine was lodged in a persistent cavity of the great omentum; entrance to which had been gained by an opening in the left half of the transverse mesocolon in the region between the greater curvature of the stomach and the transverse colon. The rarity of this observation induced a search in the literature pertaining to similar conditions and it was found that relatively few cases presenting like relations and position of the intestines have been placed on record. A search of the literature was made difficult by view of the fact that the recorded cases are listed under various titles, such as internal hernias, hernia bursa omentalis, hernia Foramen of Winslow, hernia intermesocolica, Treitz hernia, etc. The author thinks that these cases should be called hernias of the bursa omentalis.

Since all cases of more marked deviations from the normal in the position of the different parts of the alimentary canal and the mesenteries has an interest both from the developmental and from the gross anatomical view points, the latter more particularly with reference to the diagnosis of pathological conditions and to surgery of the intestine, the case under consideration seemed worthy of record. The pertinent literature is given in very brief review and this before the case in question is presented.

By way of a very general summary, it may be stated that in only five of the recorded cases was a persistent eavity of the great 
omentum noted; in four others, a partial separation of the adherent layers of the great omentum was mentioned; in twentythree of the recorded cases, the hernia entered the bursa omentalis by way of the epiploic foramen; in the same number of cases through openings in the transverse mesocolon; in three cases through openings in the walls of the great omentum; and in one case through a hiatus in the gastro-hepatic omentum. The small intestine was the viscus producing the hernia in forty-two cases, portions of the large intestine in three cases, and portions of both large and small intestines in five cases.

The cases recorded in the literature may be grouped into the following subdivisions of Hernia of the bursa omentalis:

a) Herniae entering the bursa omentalis through the foramen epiploic.

b) Herniae entering by way of an opening in the transverse mesocolon.

c) Herniae through openings in the walls of the great omentum.

d) Hernite entering the bursa ornentalis by way of an opening in the gastro-hepatic omentum.

The first record of a case in which the hernia entered through the epiploic foramen was made by Blandin ('34). He observed at an autopsy a large scgment of the small intestine in an opening in the transverse mesocolon, its point of exit from the bursa omentalis. These loops of intestine had entered the bursa omentalis through the cpiploic foramen. Rokitansky ('42) reported having scen a large portion of the small intestine strangulated in the epiploic foramen. Treitz ('57) records a case in which two loops of jejunum were found in the lesser peritoneal sac, which was entered through the epiploic foramen. He stated that he had often scen parts of the large intestine, especially a hepatic flexure or abnormal loop of the transverse colon in this forame $n$. J. Wilson Moir ('68), as quoted by Cheine, observed most of the small intestine within the lesser sac having passed in through the epiploie foramen. Novello ('81) reported a case where two meters of small intestine had passed through the epiploic foramen into the bursa omentalis. Mojoli ('84) observed a loop of the transverse colon in the cpiploic opening. Elliott-Square ('86) found at an operation "eight inches of ileum, two feet from its termination," in the epiploic foramen. This foramen was large enough to admit two fingers. Treves ('88) reported an operation at which he found the caecum, ascending, part of the transverse colon, and between two and three feet of ileum, had passed through the epiploic foramen. He noticed that the caccum was of the undescended type, and had led the hernia into the lesser sac. A part of the hernia reappeared in the greater sac through an opening in the gastro-hepatic omentum. The appendix was found at the lesser 
curvature of the stomach, near the oesophagus. Gangolphe ('90) found the greater part of the small intestine within the bursa omentalis which it had reached by way of the epiploic foramen. Neve ('92) observed at an operation that the ascending and part of the transverse colon had passed through a ring situated behind the stomach and to the right of the median line. It was large enough to admit two fingers, but he believed it to be the epiploic foramen. Rehn ('92) reports having seen parts of the small intestine in the epiploic foramen. Picardo ('93) saw a case where part of the small intestine was herniated through the epiploic foramen into the lesser sac. Stecchi ('94) had a case with small intestine coils within the small peritoneal sac which they had reached by way of the epiploic opening. Reynier ('97) writes of a case operated on by Dr. Wall and himself in which they found the greater part of the small intestine within the bursa omentalis. The epiploic foramen was the passage way for the hernia. Mori ('98) observed a case where part of the colon had passed through the epiploic foramen into the lesser sac. Rawitsch-Schtscherbo ('99) found in their case a diverticulum of the small intestine, nine centimeters long, in the foramen of Winslow. Groves and Martin ('00) had a case where parts of both small and large intestine were in a bursa omentalis hernia, entering by way of the foramen of Winslow. Adajaroff ('01) reported a strangulation of part of the small intestine in the epiploic foramen. Jeanbrau and Riche ('02) had a case where the duodeno-jejunal angle was the part in the epiploic foramen. Delkeskamp ('05) reports a case of a woman who after normal labor developed intestinal obstruction. At operation, it was found that all of the large intestine, except the sigmoid colon, and also coils of the small intestine had passed through the epiploic foramen into a "peritoneal sac of the shape of a dilated stomach." He found a common ileo-caecal mesentery and a very long sigmoid mesocolon. Carwardine ('08) writes of a case in which he found two and a half feet of ileum forming a bursa omentalis hernia by passing through the epiploic foramen. Borszéky ('12) reported a case in which he found part of the small intestine passing through the epiploic foramen into the lesser sac and out through a slit in the gastro-hepatic omentum into the greater sac.

Of the recorded cases of hernia of the bursa omentalis in which entrance to the lesser sac was found through an opening in the transverse mesocolon, Loebl ('44) was the first reporter. He observed an opening the size of the fist about the middle of the transverse mesocolon through which the greater part of the small intestine had passed into the "cavity of the great omentum." Diettrich ('47) reported a case in which there was an opening in the transverse mesocolon through which "all of the movable small intestine had passed into the bursa and out again through an opening in the omentum magnus (ligament gastro-colie) so that they hung in front of the transverse colon and free part of the great omentum." Deville ('51) observed a case in which an opening in the transverse mesocolon was found opposite to the body of the fourth lumbar vertebra. Through this had passed 
eoils of the small intestine into the lesser sae. The transerse colon descended as a sling to the level of the pelvis. Treitz ('57) reported two eases with openings in the transverse mesocolon through which the greater parts of the jejunums had reached the lesser saces and lay between the layers of the great omenta. Rembold ('65) saw in a case an opening in the transverse mesocolon through which two and a half feet of small intestine had passed into a space "between the liver and an" hour-glass stomach" (bursa). Boetteher (76) in a case found an opening larger than the size of a fist in the transverse mesorolon. It had smooth borders, and was bounded by blood vessels. Most of the small intestine had passed through into the bursa, and lay between the laycrs of the free part of the great omentum-persistent great omental cavity. Furst ('94) reported a case with a nine centimeter opening in the transverse mesocolon through which one-third of the small intestine had entered the bursa. Hakonson ('94) saw in a case of hourglass stomach great defects in the transverse mesocolon and gastrohepatic omentum. Through the first of these openings, part of the colon and coils of the small intestine had entered the lesser peritoneal sac and returned to the greater sac through the second opening to hang down in front of the stomach. Laurer ('94) writes of a case possessing similar openings. The patient had an hour-glass stomach. Part of the small intestine passed through an opening in the transverse mesocolon and out of the bursa by means of the opening in the lesser omentun. Sunrberg (97) reports a case with a lefect of the transverse mesocolon measuring five by ten centimeters. Through this the jejunum and most of the ileum entered the omental bursa. Here again the coils reappeared in the greater peritoneal sac through an opening in the lesser omentum. Akerman ('02) saw an opening the size of a fist in the transverse mesocolon of a patient at an operation. The greater part of the ileum, the caecum, and the lower end of the ascending colon had passol through this opening into the omental bursal and then part of the hernia returned to the greater sae by means of the epiploic foramen. Narath ('93) names the opening into the bursa in the case recorded by him the "recessus duodeno-jejunalis." Schumacher suggests designating it "the radix of the mesocolon transversum." Most of the coils of the small intestine passed through this opening into the bursa omentalis, and then reappeared in an opening in the gastro-hepatic omentum, certain of the coils hanging in front of the stomach. Bastianelli ('04) describes a case of retroposition of the colon. The short transverse mesocolon had an opening through which a coil of the small intestinc had passed. Schwalbe ('04) found in a subject at autopsy a five centimeter opening in the transverse mesocolon through which most of the small intestine had passed into the omental bursa. Two coils occupied a separation of the layers of the great omentum at its upper part, the lower part of the membrane adhering to the abdominal wall. The transverse colon was of a long U-shape reaching to the pelvis. The limbs of the $U$ ran parallel to the ascending and descending colon. The hepatic and splenic flexures were normal. Ihseche ('04) saw in a 
case a four centimeter opening in the transverse mesocolon through which most of the small intestine reached the lesser peritoneal sac. Some of the coils returned to the greater sac through an opening in the gastro-hepatic omentum and were in relation with the lesser curvature of the stomach. Chalmers ('05) reported a case as a "duodenal hernia through the recessus intermesocolica." He describes an opening in the transverse mesocolon bounded by blood vessels, and measuring about five centimeters in diameter. Two coils of small intestine passed through it into the lesser sac. Perman ('96) records a case having an opening four fingers wide in the transverse mesocolon to the right of the middle line of the body. Through this opening, all of the jejunum and most of the ileum passed into the bursa omentalis. A large opening in the lesser omentum permitted coils to reenter the greater peritoneal sac. Enderlin and Gasser ('06) report cases of intestine lying in the lesscr' sac. These were most likely far advanced types of "herniae mesocolic media." Mayo ('09) describes a case in which all of the movable small intestine, except the first three and the last twelve inches entered the bursa omentalis through the mesocolic omentum, and escaped through an opening in the gastro-hepatic omentum. In a second case he writes of an opening in the transverse mesocolon in front of the ligament of Trcitz, measuring four inches. Five feet of jejunum passed through this opening, carrying with it a layer of the peritoneum derived from transverse mesocolon and bulging out the gastro-hepatic omentum over the lesser curvature of the stomach. This last described hernia having other coverings than the walls of the bursa should probably not be classed as a true bursa omentalis hernia, but rather with those mentioned of Enderlin and Gasser. Prutz ('09) observed a case in which all of the movable small intestine except a terminal twenty inches of ileum had passed through an opening in the transverse mesocolon into the bursa omentalis and then out through an opening in the lesser omentum to hang in front of the stomach. Sehumacher ('09) reported finding in a patient an opening measuring five long by one and a half centimeters broad in the transverse mesocolon by way of which the jejunum cntered the bursa omentalis and lay between the layers of the great omentum. Stoltzenberg ('10) saw in a case an opening measuring five inches wide in the transverse mesocolon through which the ileum had passed into the bursa. Many of the coils returned to the greater sac by an opening in the lesser omentum. The transverse colon was of a long U-shape, and reached the pelvis as in Schwalbe's case.

Under the variety of bursal herniae that enter by way of an opening in the walls of the great omentum, Baugrand ('60) reports a case with an opening in the great omentum through which the ileum had passed into its interior. Wandel ('03) had a patient with volvulus. At autopsy, he found a common mesentery and an opening in the front wall of the great omentum through which coils of the small intestine entered a cavity between the layers of the great omentum. Hilgreneiner ('03) presents the case of a similar hernia, except that the opening was in the lower part of the posterior wall of the great omentum. 
The relative frequency in which openings in the gastrohepatic omentum give exit to herniae which have entered the bursa omentalis by means of openings in the transverse mesocolon makes one using such an opening to enter the bursa of special interest. Berg ('97) records such a case. He found a large opening in the gastro-hepatic omentum through which a meter of small intestine and a coil of the colon had entered the bursa.

A number of other cases were found in the literature consulted by the writer which were so indefinite in anatomic data that they are omitted from this brief review.

\section{DESCRIPTION OF THE AUTHOR'S CASE}

The subject was a well developed male; the record given to us gave his age as fifty-seven; the cause of death as rheumatism. Besides the condition about to be described, very interesting developmental defects were found in the vascular and urogenital systems. The heart received a right as well as a left superior vena cava, and the kidneys possessed double hili and ureters.

Upon opening the abdomen, part of the colon was observed lying anterior to the exposed part of the liver and stomach. On tracing this part of the colon beneath the left costal margin, it was determined that the gut was folded on itself at the oesophageal end of the stomach and then descended in front of the stomach and right portion of a very large great omentum. This descending part was thus parallel to the ascending colon. When this descending loop reached the level of the fourth lumbar vertebra it was folded under until it reached the right margin of the great omentum beneath which it disappeared.

Upon raising the great omentum to follow the colon it was discovered that all of the small intestine except the duodenum and the terminal ten centimeters of the ileum were within the great. omentum, which thus formed a hernial sac. The intestine had entered this sac by an opening in the transverse mesocolon corresponding to the ventral surfaces of the third and fourth lumbar vertebrae. The dorsal border of the opening was found to be a thickened band, running parallel to which was an anastomosing branch between the middle and left colic arteries. On the anterior surface of the great omentum were relatively large arteries derived from the right and left gastro-epiploics. The colic 
attachment of the great omenturn was limited to the left portion of the transverse colon, as seems to be the rule in cases with very long transverse colons.

Returning to the tracing of this last structure, it was found to cross the vertebral column behind the omental sac and ascend parallel to the descending colon to a normal splenic flexure. Thus the transverse colon was of the U-shape described in the cases of Schwalbe, Stoltzenberg, and others. The caecum, ascending, and all of the transverse colon except the last described ascending limb were very much dilated and devoid of saculation. Tho colon measured one and a half meters, one-half of the length being in the transverse colon. The small intestine was normal except in relations. The stomach was small and concealed by the colon as previously described, except for a small area of the left side.

I long $\mathrm{V}$ - or U-shape transverse colon is not very rare. Huntington states that the relatively large fetal liver gives an oblique direction to the developing transverse colon. With the latter's continued growth, it may form an arch with the summit in the pelvis. This long arch usually disappears with the relative decrease in size of the liver in the later stage of development. Where it persists in the adult it usually, as in the writer's case, forms a large part of the extra length of the large intestine found in these individuals. Transverse colons of this shape are normal in the baboon.

In the reported cases of bursal herniae passing through openings in the transverse mesocolon in relatively few cases was a $\mathrm{V}$ - or U-shape transverse colon noted, so the author doubts any causal relationship.

From a study of recorded cases, it seems clear that more than one factor is responsible for a hernia of the bursa omentalis. Moynihan speaks of the frequency of four abnormalities noticed in these cases, viz., the presence of a common mesentery; the absence of fusion of the ascending mesocolon to the primary peritoneum of the posterior abdominal wall; unusually large epiploic foramen, and a very long mesentery. Unfortunately, so few of the reporters have given sufficient anatomical data 
in their papers to. suffice for statistics, that the writer finds himself unable to state that these conditions are frequent. None of the four abnormalities were present in the case under consideration.

The majority of the observers assign as the reason for the existence of the openings in the transverse mesocolon and omenta an atrophic process involving the area of the future opening and, this atrophy occurring so frequently in essentially the same places has led certain of these observers to postulate also that a slight embryonic defect in these membranes must mark the site for this atrophy.

Stoltzenberg suggests that such a defect in the transverse mesocolon would result from the rotation of the colon He reports having found in a four month fetus a small opening in the transverse mesocolon against which lay the two highest loops of the jejunum. Also that there was observed a relatively thin arca in this location in the membranes of all fetuses and young infants he had been able to investigate at post mortems. Schwalbe also writes of having observed such depressions. The possibility has suggested itself to the author that such depressions might be explained by assuming that the arteries as they pass ventral in the membrane to reach the viscera cause slight ridges to appear in the mesenteries, the areas between appearing as depressions. The space between the anastomotic branches of the middle and left colic arteries might thus become such a slightly depressed area in the peritoneum. A number of observers have noted that these two arteries bound the opening found in the transverse mesocolon in these cases.

Stoltzenberg has pointed out that this area between these vessels may perhaps present a region in which the abdominal pressure would find a path of least resistance to what he terms the "stomach-liver niche," located above the transverse colon. He fully appreciates that this pressure would be great in the relatively small abdominal capacity for the rapidly developing coils of the intestine as found in a fetus.

On the other hand, these bursal herniae have so frequently returned to the greater peritoneal sac through an opening in 
the gastro-hepatic omentum not bounded by vessels; in Berg's case, the hernia entered the lesser sac at this place, and in Blandin's case, in which the hernia, after having entered by way of the epilotic foramen, emerged by an opening in the transverse mesocolon; that the writer thinks this explanation of fetal pressure in an upward direction on vessel bounded depressions is inadequate. Postnatal prossure as a cause has perhaps been more frequent than prenatal. The clinical data in these cases show the frequency of ulcer, cancer, and hour-glass stomach in these subjects; conditions in which one would have violent romiting and peristalsis to increase abdominal pressure.

The fact that in only a few cases have these hernias occupied the cavity of the great omentum which exists during the first and often the second year of life seems to the writer a strong point in favor of postnatal origin. Why may not gravity bring the intestinal coils of such a hernia down into this space instead of their remaining in the retrogastric portion of the bursa omentalis as is true in most of these cases? The presence of long and common mesenteries noted in a number of these cases would make this possible. Again, this form of hernia has not been observed in any subject in the first few years of life. The vast majority hare been adults.

It seems plausible that in the cases where the hernias were found in a cavity of the great omentum these individuals possessed a cavity long after the normal time of fusion of the lamellae of the great omentum. When pressure atrophy effected an opening into the bursa omentalis of such subjects coils of the intestine would gravitate into the lowest part of that cavity. 


\section{LITERATURE CITED}

Certain of the references given, it has been impossible to consult in the original.

Ackerman, J. H. 1902 Intraabdominaller Bruch durch eine oefinung im mesocolon transversum. Nord. Med. Archiv. Chir. Heft 2, No. 9.

Adajaroff, Chr. 1901 Operationoto letehenie na zapletenita tcherva. Medizinski Napredak. Nr. 11 and 12, p. 632.

Bastianelli, P. 1904 Strozzamento acuto di anse del tennue attraverso ad una fessura congenita del mesocolon traverso essendo il colon traverso in retropositione. II. Policlinico, sez. chir., vol. 11, p. 56.

Bavgrand 1860 Quoted from Duchaussoy, Etanglements internes. Mem. de l'acad. imp. de med. T. 24, p. 357.

Berg 1907 Zwei Fälle von Achsendrehung des Magens, Verhandl. der Deutsch. Gesellach fur Chir., 33 Kongress, S. 213.

Blandin, Ph. Fred. 1834 Traite d'anatomie topographique ou Anatomie du Corps humain. 2 edit.

Boetтcher, A. 1878 Hernia bursac omentalis mit im mesocolon tranversum befindlicher Bruchpforte. Archiv. fur Pathol. Anatomie (Virchow) Bd. 72 , S. 642 .

Borszéky, KarL 1912 Pathogenese der Hernien der Bursa omentalis mit normaler Bruchpforte. Beitrage zur klin. Chir., Bd. 77, S. 438.

Carwardine, T. 1908 Herria through the foramen of Winslow. London Lancet. Part 2, p. 1213.

Chalmers, A. J. 1905 Duodenal hernia through recessus intermesocolica. Jour. of Path. and Bact., vol. 10, p. 287.

Delkeskamp 1905 Zur Kasuistik der inneren Hernien, speciall der Hernia foraminis Winslowii. Beitrage zur Klin. Chir., Bd. 47, No. 3, S. 644.

Deville 1851 Bull. de la societé anat. Paris, 26.

Diettrich. 1847 Beitrage zur path. Anatomie. Vierteljahrsschr. f. prakt. Heilkunde. Prag., No. 1, S. 125.

Elciotr-Square, J. 1886 A case of strangulated internal hernia into the foramen of Winslow. Brit. Med. Jour., vol. 1, p. 1163.

Enderlen und Gasser 1906 Stereoskopbilder zur Lehre der Hernien. Jena, S. 72 .

Furst 1894 Ett Fall af hernia intraabdominalis. Nord. Med. Arkiv. N. F., Bd. 4, H. 3.

Gangolphe, M. 1890 Hernia étranglee á travers l'hiatus de Winslow. Lyon Medical, v. 64, p. 607.

Groves, H. J. F. and Martin, R. H. 1900 A case of hernia into the foramen of Winslow. Australian Med. Gaz., Sidney, No. 19, p. 413. 
HAkovson. 1894 Fall af ventriculus bisaccatus med torsion af pyloris afdelningen samt egendomliga lüge forandringar af närliggande viscera. Nordiski Medicinski Arkiv. N. F., Bd. 4, IT. 4, Nr. 21.

Hilgreneiner 1903 Zur Kasuistik der Hernia bursae omentalis. Prager Med. Wochenschr., v. 28, Nr. 43.

Huntington, Geo. S. 1903 Anatomy of the peritoneum and abdomen. Tea Bros., Philadelphia.

Inseche, O. 1904 Innaugural disscrtation. Halle. Quoted by Stoltzenberg.

Jeanbrat, E. et Riche 1906 L'occlussion Intestinale. Rev. de Chir., v. 33, p. 618 .

LaURer 1894 Ein Fall von Hernia mesocolonialis. In. Diss. Greifswald.

JoenL 1814 Zeitschr. d. k. k. Grsellschaft d. Aerzte zn Wein. 1. Jahrg. Bd. 1, S. $151-154$.

Mayo, Wm. J. 1909 Mesocolic or retrogastric hernia. Annals of Surgery, Philadelphia, no. 49, p. 487.

Morr, J. Wilson 1868 Quoted by Chcine. Anatomical description of a case of intraperitoneal hernia. Jour. of Anat. and Physiol., vol. 2, p. 218.

Mosor., G. 1884 Storia di une occlusione lenta dell' intestine cagionate dal passagio e dallo strozzamento di un'ansa del crasso attraverso il foramen del Winslow. Rivista Clin. di Bologna, No. 4, p. 605-622.

Mont. 1898 Ernia pel foramen di Winslow. Gass. Med. Lombardo. Milano. v. 57, p. 257.

Moyniman, B. G. A. 1906 Retroperitoneal hernia. London.

Naratr. 1903 Zur Pathologia und Chirurgie der Hernia Duodeno-jejunalis. Arch. f. klin. Chir., Bd. 71, H. 4.

Neve, A. 1892 Hernia into the foramen of Winslow. London, Lancet, No. 1, p. 1175 .

Nonvelito, A. 1881 Gas. med. Ital. prov. Venete. Padova. No. 38, p. 313-31j.

Perman. 1906 Ett fall af intraabdominelt bråck genom en öppning i mesocolon transversum och omentum minus. Hygiea, 2 F., Bd. 6, H. 5, p. 467.

PICARdo, J. S. 1893 Un caso de hernia interna retroperitoneal por el hiatus de Winslow. Rev. de la Socied. Med. Argentina, Buenos-Ayres.

Prutz, W. 1910 Verletzungen und Krankheiten des Netzes und Mesenteriums. Deutsche Chirurgie. Lief. $46 \mathrm{k}$, S. 104.

RAWitsei-Schtscherbo 1899 Lin Fall von Undurehgangigkeit des Darmes bedingt durch Einklcmmung eines Dünndarmdivertikels in Foramen of Winslow. Wojenno Medicinski Shurnal. April. p. 627.

Renv 1892 Ueber Eehandlung des acuten Darmverschluss. Archiv. de Langenbeck, Bd. 48, p. 310 . 
Remaolis 1865 Ein fall von Achsendrehung des Duodenum. Oester. Zeitschr. fur prackt. Heilkunde. Nr. 6u. 7, S. 108-124.

Rerner, PaUl 1897 Hernia de l'intestin grele dans l'hiatus de Winslow. Soc. de Chir., p. 627.

Rokitaskr, Cart 1842 Handbuek der Pathol. Anatomy. Wein, S. 218.

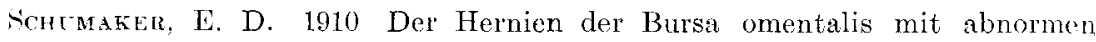
Fintrittspforten. Beitrage zur klin. Chir., Bd. 66, p. 507.

STECHI. R. 1894 Ernia retroperitoncale atraverso il forame del Winslow. Ita Clin. Chir. Milano, v. 2, p. 653-664.

SToltzenberg, F. 1910 Uber Hernia bursa omentalis mesocolica. Areh. fur path. Inat.-Virehow. Bd, 201, s. 470.

Suxdmexg 1897 Hernia bursac omenti med brächport i mesocolon transversum och sekundart genomenbrott af brăcket genom omentum minus. Cpsala lakaform. I3d. 2, H. 9, S. 562 .

SCHWALsk, E. 1904 Intraabdominal Hernia der Bursa omentalis bei geschlossenem Foramen Winslowii. Arch. f. pathol. Anat.-Virchow. Bd. 177, s. 561 .

Trartz, E. W. 1857 Hernia retroperitonealis, ein Beitrage zur Gesicht inneren Hernien. Prague.

Treves. Fredrich 1888 Hernia into the foramen of Winslow. London, Lancet, October 13, p. 701.

Wandel 1903 Uber volvulus des Caecum und colon ascendens. Mitt. aus den Grenzgeb der Med. u. Chir. Bd. 11, H. 2, S. 53. 